\title{
Randomized Controlled Trial of Humidified High-Flow Nasal Oxygen for Acute Respiratory Distress in the Emergency Department: The HOT-ER Study
}

\author{
Peter G Jones MSc MBChB, Sinan Kamona MBChB, Owen Doran MBChB, Frann Sawtell RN, \\ and Margaret Wilsher MD MBChB
}

\begin{abstract}
BACKGROUND: Humidified high-flow nasal cannula (HFNC) is a novel method of oxygen delivery with increasing use in emergency departments and intensive care settings despite little evidence showing benefit over standard oxygen delivery methods (standard $\mathrm{O}_{2}$ ). The aim of this study was to determine whether HFNC compared with standard $\mathrm{O}_{2}$ given to subjects in acute respiratory distress would reduce the need for noninvasive ventilation or invasive ventilation. METHODS: This was a pragmatic open randomized controlled trial in adult subjects with hypoxia and tachypnea presenting to a tertiary academic hospital emergency department. The primary outcome was the need for mechanical ventilation in the emergency department. RESULTS: We screened 1,287 patients, 322 met entry criteria and 19 were excluded from analysis. Of these, 165 randomized to HFNC and 138 to standard $\mathrm{O}_{2}$ were analyzed. Baseline characteristics were similar. In the HFNC group, 3.6\% (95\% CI 1.5-7.9\%) versus 7.2\% (95\% CI 3.8-13\%) in the standard $\mathrm{O}_{2}$ group required mechanical ventilation in the emergency department $(P=.16)$, and 5.5\% $(95 \%$ CI $2.8-10.2 \%)$ in HFNC versus $11.6 \%\left(95 \% \mathrm{CI}\right.$ 7.2-18.1\%) in the standard $\mathrm{O}_{2}$ group required mechanical ventilation within $24 \mathrm{~h}$ of admission $(P=\mathbf{. 0 5 3})$. There was no difference in mortality or stay. Adverse effects were infrequent; however, fewer subjects in the HFNC group had a fall in Glasgow coma score due to $\mathrm{CO}_{2}$ retention, $0 \%(95 \%$ CI 0-3\%) versus $2.2 \%$ (95\% CI 0.4-6\%). One in 12 subjects did not tolerate HFNC. CONCLUSIONS: HFNC was not shown to reduce the need for mechanical ventilation in the emergency department for subjects with acute respiratory distress compared with standard $\mathrm{O}_{2}$, although it was safe and may reduce the need for escalation of oxygen therapy within the first $24 \mathbf{h}$ of admission. Key words: emergency service; hospital; respiratory distress; humidified high-flow nasal oxygen; noninvasive ventilation; randomized controlled trial; equipment and supplies. [Respir Care 2016;61(3):291-299. (C) 2016 Daedalus Enterprises]
\end{abstract}

\section{Introduction}

Humidified high-flow nasal oxygen (HFNC) is a novel method of oxygen delivery that is increasing in popularity

Drs Jones, Kimona, and Doran and Ms Sawtell are affiliated with the Department of Adult Emergency Medicine, and Dr Wilsher is affiliated with the Respiratory Medicine Department, Auckland City Hospital, Auckland, New Zealand.

This study was supported by 2 competitive public good grants, from the $\mathrm{A}+$ Trust for a pilot study to inform the initial sample size calculation and from the Greenlane Research and Education Fund for the study proper. The authors have disclosed no conflicts of interest.

Dr Jones presented interim results of the study at the International Conference on Emergency Medicine, held on June 13, 2014, in Hong Kong. despite a paucity of evidence of its benefit over standard oxygen delivery methods (standard $\mathrm{O}_{2}$ ). HFNC uses a large bore nasal cannula to deliver up to $60 \mathrm{~L} / \mathrm{min}$ of heated humidified gas, while the $\mathrm{F}_{\mathrm{IO}_{2}}$ can be titrated from .21 to 1 as needed. ${ }^{1}$ Purported benefits include washout of nasopharyngeal dead space, attenuation of inspiratory resis-

\footnotetext{
Supplementary material related to this paper is available at http:// www.rcjournal.com.

Correspondence: Peter G Jones MSc MBChB, Director of Emergency Medicine Research, Adult Emergency Department, Auckland City Hospital, Park Road, Grafton, Auckland 1142, New Zealand. E-mail: peterj@adhb.govt.nz.
}

DOI: $10.4187 /$ respcare. 04252 
tance, improved pulmonary compliance, and provision of a small amount of CPAP to facilitate alveolar recruitment. ${ }^{2}$ Humidification and heating may also prevent mucosal dehydration, maintain ciliary activity, reduce heat loss, and minimize atelectasis and tracheitis. ${ }^{3}$

Some studies suggest that HFNC reduces ventilator days, re-intubations, and the need for invasive ventilation, ${ }^{4-6}$ whereas other studies have not shown a benefit. ${ }^{7,8}$ Four recent systematic reviews concluded that there was insufficient evidence supporting HFNC and highlighted a lack of randomized, controlled trials. ${ }^{1,9-11}$ In the only emergency department study of HFNC, a case series of 17 emergency department subjects were switched from standard $\mathrm{O}_{2}$ to HFNC, with improvements shown in dyspnea scores, breathing frequency and oxygen saturations. ${ }^{12}$

Patients with acute hypoxia and respiratory distress presenting to the emergency department may need noninvasive (NIV) or invasive positive-pressure ventilation requiring a high level of nursing care. Patients requiring these therapies may have prolonged lengths of stay in the emergency department when high dependence beds are not available, with subsequent impact on emergency department resources. These treatments also risk iatrogenic barotrauma, aspiration, nosocomial infection, and ventilator dependence. Conversely, HFNC requires less intensive nursing support and can be provided in general ward settings. If HFNC can reduce the proportion of patients who require invasive positive-pressure ventilation or NIV in the emergency department, then there are potential benefits with respect to reducing harm to patients, reducing the use of emergency department resources, shorter lengths of emergency department stay (LOS), and improved availability of high dependence beds in the hospital.

The aim of this study was to determine whether HFNC compared with standard $\mathrm{O}_{2}$ would reduce the need for NIV or invasive positive-pressure ventilation in the emergency department. The primary outcome was conversion to NIV or invasive positive-pressure ventilation. The secondary outcomes were the emergency department and hospital lengths of stay, 90-d mortality, adverse effects in hospital, and the participant experience.

\section{Methods}

This was a single center, pragmatic open prospective randomized controlled trial. Auckland City Hospital, New Zealand, is a tertiary academic inner-city hospital catering to adult patients age 15 and older. The emergency department received 59,335 presentations in 2013 with an approximate $40 \%$ admission rate.

We included subjects who had $\mathrm{S}_{\mathrm{pO}_{2}}$ of $\leq 92 \%$ on air ( $\leq 90 \%$ if known chronic carbon dioxide $\left[\mathrm{CO}_{2}\right]$ retention) and a breathing frequency of $\geq 22$ breaths/min either prehospital or upon arrival to the emergency department. We

\section{QUICK LOOK}

\section{Current knowledge}

High-flow oxygen by nasal cannula (HFNC) is a noninvasive method of respiratory support may improve ventilation by flushing of the upper airway dead space and improves oxygenation by meeting the patient's demands with enriched oxygen. In some settings, a small amount of end-expiratory pressure can develop, further improving oxygenation. Heat and humidity are essential for patient tolerance and comfort.

\section{What this paper contributes to our knowledge}

HFNC was not shown to reduce the need for noninvasive or invasive mechanical ventilation in emergency department subjects with acute respiratory distress compared with standard oxygen therapy. HFNC reduced the need for escalation of oxygen therapy within the first $24 \mathrm{~h}$ of admission. No clinically important adverse events were associated with HFNC use; however, 1 in 12 subjects were intolerant of therapy.

excluded patients who were intubated pre-hospital; required intubation or NIV immediately upon arrival; had bullous lung disease, pneumothorax, facial abnormalities precluding the use of nasal prongs, facial or intracranial trauma, facial or trans-nasal neurosurgery (within 6 weeks); or had epistaxis (within 2 weeks). We also excluded patients who had a prior decision for palliative care only or who had previously been enrolled.

HFNC was delivered using an Optiflow nasal interface connected to the PT101AX (Airvo1) or PT101AZ (Airvo2) humidifier (Fisher \& Paykel Healthcare, Auckland, New Zealand). Starting flow was $40 \mathrm{~L} / \mathrm{min}$, with gas temperature $37^{\circ} \mathrm{C}$ and $\mathrm{F}_{\mathrm{IO}_{2}}$ of .28 (approximating to $2 \mathrm{~L} / \mathrm{min}$ via standard nasal prongs ${ }^{13}$ ). All nurses, emergency specialists, and residents were trained in the use of HFNC and the study procedures before inception of the study and at regular periods throughout the course of the study. Standard $\mathrm{O}_{2}$ was via a Hudson mask, Venturi device, or standard nasal prongs using wall oxygen titrated with a flow meter (1-15 L/min). After enrollment, the $\mathrm{F}_{\mathrm{IO}_{2}}$ was titrated according to clinical need. Subjects with known chronic hypoxia had a target maximum $\mathrm{S}_{\mathrm{pO}_{2}}$ of $93 \%$ or their last known resting oxygen saturation when well.

For subjects who were able to consent or had a family member or other surrogate available, informed consent was obtained before enrollment. A purpose-built program in Microsoft Access 2003 based on a random number generator was used for randomization. For subjects who were too unwell to consent and with no surrogate available, a series of sealed opaque envelopes with treatment alloca- 
tion generated using the same randomization software were available to clinicians to use at the bedside in the resuscitation area. Clinicians took the next envelope in a consecutive sequence when a potentially eligible subject arrived in the resuscitation room. Consent was obtained retrospectively as soon as practical after the subject's acute illness had resolved. A questionnaire to assess the subject's experience was performed as soon as practicable after randomization. Enrollment was 24 h/day, 7 days/week by clinical staff. Participants, treating clinical staff, and those responsible for data entry were not blinded to the interventions; however, treatment allocation was masked before analysis.

The study period was from July 2012 to May 2014. Data were recorded in the clinical record and extracted by the study coordinator or an assistant onto a standard data extraction form and then into a purpose-built electronic database (Microsoft Access 2003).

The primary outcome was conversion to NIV or invasive positive-pressure ventilation using the British Thoracic Society's guidelines ${ }^{14}$ : persistent or worsening hypoxemia, worsening tachypnea, rising arterial $\mathrm{P}_{\mathrm{CO}_{2}}$, or persistent respiratory acidosis with $\mathrm{pH}<7.30$ despite 30 min of optimized standard acute medical therapy; worsening fatigue or confusion attributable to respiratory failure; or a decision by the treating clinician that escalation of therapy is in the subject's best interest. The choice of NIV, either CPAP or bi-level positive airway pressure was at the discretion of the treating clinician. CPAP was started at $5 \mathrm{~cm} \mathrm{H}_{2} \mathrm{O}$, whereas bi-level positive airway pressure was started at $10 \mathrm{~cm} \mathrm{H}_{2} \mathrm{O}$ (inspiratory) and $5 \mathrm{~cm} \mathrm{H}_{2} \mathrm{O}$ (expiratory). The device used to deliver CPAP or bi-level positive airway pressure was the BiPAP Vision (Respironics, Pittsburgh, Pennsylvania). The criteria for invasive positive-pressure ventilation were: criteria for NIV met and the clinician anticipates that invasive ventilation will be required; failure of NIV; or inability of the subject to maintain his/her own airway or manage his/her own secretions or subject fatigue or confusion attributable to respiratory failure.

Emergency department and hospital lengths of stay were recorded in the hospital's electronic patient tracking system. Ninety-day mortality was checked using the National Health Index number, a unique identifier for patients across multiple databases in New Zealand's health system. Adverse effects sought were pneumothorax, subcutaneous emphysema, nasal pressure sore, apnea, drop in Glasgow coma score of 2 or more points, and basic physiological variables. Their presence or absence was determined from the subject record and/or radiology reports.

The participant experience was explored using a purpose-designed questionnaire with 6 questions assessing the participant's perception of the comfort and effectiveness of the oxygen delivery system (see the appendix at http://www.rcjournal.com). A 5-point Likert scale from strongly disagree to strongly agree was used. Two further free-text questions prompted for both good and bad effects of the oxygen therapy. The questionnaire was piloted before study commencement on subjects who would have been eligible for the study proper.

\section{Post Hoc Outcomes}

During the study, it became apparent that some participants received NIV soon after leaving the emergency department, which was unexpected when we designed the study. To determine how many subjects also received mechanical ventilation within the first $24 \mathrm{~h}$ of admission, we conducted a post hoc analysis. We also explored the ICU admission rate and in-hospital mortality, which were outcomes that were not specified in the trial protocol.

\section{Statistics}

Proportions $(95 \% \mathrm{CI})$, mean $(95 \% \mathrm{CI})$, and median (interquartile range) were used where appropriate to describe the data. Analysis was performed using the chi-square or Fisher exact test for proportions and Student $t$ test or the Mann-Whitney $U$ test for continuous variables as appropriate to the distribution of the data. Likert scales were dichotomized into favorable (best 2) and unfavorable (worst 3) or unfavorable (worst 2) and favorable (best 3) responses for positive and negative questions, respectively. All analysis was intention-to-treat and undertaken with IBM SPSS 22 (IBM, Armonk, New York). A feasibility study informed the sample size calculation. Of $180 \mathrm{pa}-$ tients screened, $58(32 \%)$ met eligibility criteria. Of the eligible subjects, 14 (24\%) were treated with NIV. A clinically important reduction in the rate of NIV was taken as $33 \%$. To detect this difference with $80 \%$ power at an $\alpha$ of 0.05 , approximately 390 subjects would be required in each arm of the study (Power and Sample Size 3.0.2).

The study was approved by the institutional review board, and ethics approval was obtained from the Northern X Committee (NXT 10/12/121). The trial is registered with the Australian and New Zealand Clinical Trials Registry (ACTRN12610000964011). All adverse events were reported to an independent data safety monitoring board composed of 2 independent ICU specialists. After the first 200 subjects, the data safety monitoring board reviewed the interim results and recommended continuing the study.

\section{Results}

The selection of participants in the study is shown in Figure 1. During the recruitment period, 1,287 subjects were formally screened, 715 did not meet entry criteria, 


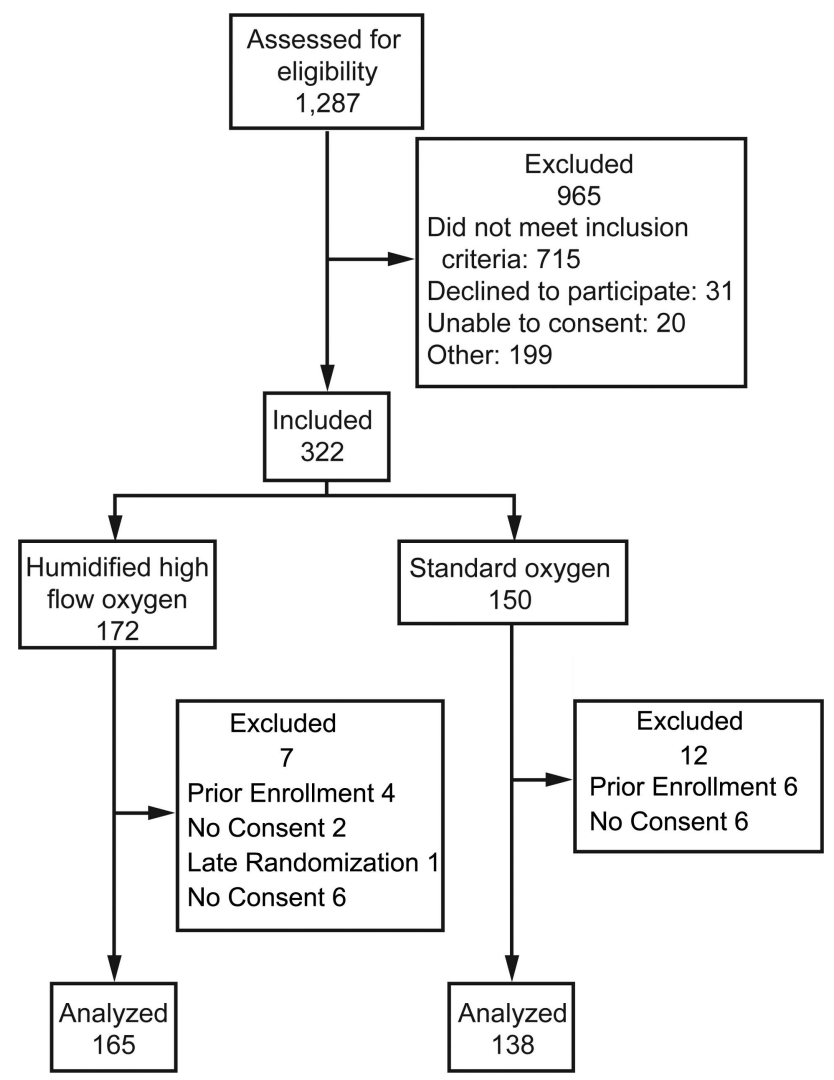

Fig. 1. Flow chart.

250 were excluded, and 322 were randomized: 172 to HFNC and 150 to standard $\mathrm{O}_{2}$. After randomization, 7 HFNC and 12 standard $\mathrm{O}_{2}$ participants were excluded from analysis. This meant that 303 subjects were analyzed, 165 in the intervention group and 138 in the standard care group. The groups were similar at baseline with respect to demographics and physiology, except for heart rates, which were higher at study entry in the standard $\mathrm{O}_{2}$ group (Table 1 and Fig. 2). The groups were similar with respect to the initial working diagnosis, investigations, and other treatments (Table 1).

Fourteen participants did not tolerate HFNC and were placed on standard $\mathrm{O}_{2}$ after periods lasting $<30$ min ( 9 participants), 30-60 min (4 participants), and $120 \mathrm{~min}$ (1 participant). Two other participants in this group had treatment changed to standard $\mathrm{O}_{2}$ by the treating clinician. Four participants did not receive HFNC because they were rapidly transferred to an in-patient ward or ICU before treatment commencing (2 participants), or they did not require any supplemental oxygen by the time enrollment was complete ( 2 participants). In the standard $\mathrm{O}_{2}$ group, 5 participants did not require supplemental oxygen after enrollment. All participants were analyzed according to their initial treatment allocation.

\section{Outcomes}

The primary and secondary outcomes are shown in Table 2. There was no difference between the groups in the proportion of subjects requiring NIV or invasive positive-pressure ventilation in the emergency department: $6 / 165,3.6 \%$ (95\% CI 1.5-7.9\%) in the HFNC group versus $10 / 138,7.3 \%$ (95\% CI $3.8-13 \%$ ) in the standard $\mathrm{O}_{2}$ group $(P=.16)$.

There was also no difference in the emergency department LOS, with a median (interquartile range) of 4.5 (3.65.8) $\mathrm{h}$ in the HFNC group versus 4.9 (3.6-5.9) $\mathrm{h}$ in the standard $\mathrm{O}_{2}$ group $(P=.32)$. Similarly, the median (interquartile range) hospital LOS was $5.0(2.8-8.3) \mathrm{d}$ in the HFNC group and $5.6(2.8-9.2) \mathrm{d}$ in the standard $\mathrm{O}_{2}$ $(P=.43)$. At $90 \mathrm{~d}, 35 / 165,21.2 \%$ (95\% CI $15.6-28.1 \%)$ in the HFNC group had died compared with $24 / 138,17.4 \%$ (95\% CI 11.9-24.6\%) in the standard oxygen delivery group $(P=.40)$.

One participant in the standard $\mathrm{O}_{2}$ group became apneic. Seven participants had a reduction in Glasgow coma score of $\geq 2$ points. Three of these were thought to be due to acute hypercapnia, and all were in the standard $\mathrm{O}_{2}$ group, $2.2 \%(95 \%$ CI $0.4-6 \%)$ versus $0 \%(95 \%$ CI $0-3 \%)$ in the HFNC group $(P=.09)$. No other adverse effects were seen.

\section{Physiology}

Figure 2 shows how the physiologic variables changed over time for both groups. Participants in the HFNC group on average tended to receive lower $\mathrm{F}_{\mathrm{IO}_{2}}$ in the first $3 \mathrm{~h}$ and had correspondingly lower $\mathrm{S}_{\mathrm{pO}_{2}}$ values, with no difference in breathing frequencies (Table 3).

\section{Participant Experience Survey (Appendix)}

Only 158/303, 52.2\% (95\% CI 47-58\%) participants completed the survey (Table 4). The reasons for not completing the survey were: inability to remember treatment $(n=70)$, reason not stated $(n=60)$, declined $(n=12)$, and transferred to another hospital $(n=3)$. A higher proportion of participants found standard $\mathrm{O}_{2}$ more comfortable than HFNC: $55 / 64,85.9 \%$ (95\% CI $75-93 \%$ ) versus 69/94, 73.4\% (95\% CI 64-81\%). Conversely, more subjects in the standard $\mathrm{O}_{2}$ group felt that their breathing did not improve: $18 / 63,28.6 \%$ (95\% CI $19-41 \%$ ) versus $19 / 93,20.4 \%$ (95\% CI 13-30\%). Fewer participants in the HFNC group felt their nose or mouth dried out: 28/94, $29.8 \%$ (95\% CI $21-40 \%$ ) versus $29 / 64,45.3 \%$ (95\% CI $34-57 \%), P=.046$. A high proportion of both groups would be happy to receive the same oxygen therapy again, with more participants in the standard $\mathrm{O}_{2}$ group expressing this thought: $57 / 64,89.1 \%$ (95\% CI $79-95 \%$ ) versus 
HFNC IN THE EMERGENCY DEPARTMENT

Table 1. Baseline Characteristics, Initial Diagnosis, Investigations, and Treatments in the Emergency Department

\begin{tabular}{|c|c|c|}
\hline Characteristic & $\operatorname{HFNC}(n=165)$ & Standard $\mathrm{O}_{2}(n=138)$ \\
\hline Age, mean \pm SD y & $74.6 \pm 15.6$ & $72.2 \pm 16.8$ \\
\hline Male sex, $n, \%(95 \% \mathrm{CI})$ & $73,44.2(37-52)$ & $71,51.5(43-60)$ \\
\hline \multicolumn{3}{|l|}{ Ethnicity, $n, \%(95 \%$ CI) } \\
\hline European & $108,65.5(58-72)$ & $91,65.9(58-73)$ \\
\hline Pacific peoples & $31,18.8(14-25)$ & $15,10.9(7-17)$ \\
\hline Maori & $16,9.7(6-15)$ & $13,9.4(5-16)$ \\
\hline Asian & $10,6.1(3-11)$ & $18,13(8-20)$ \\
\hline \multicolumn{3}{|l|}{ Smoking history, $n, \%$ (95\% CI) } \\
\hline Current & $20,12.1(8-18)$ & $22,15.9(11-23)$ \\
\hline Former & $82,49.7(42-57)$ & $66,47.8(40-56)$ \\
\hline No. of comorbidities, median (IQR) & $6(4-9)$ & $7(4-10)$ \\
\hline \multicolumn{3}{|l|}{ Inclusion criteria, mean $(95 \% \mathrm{CI})$} \\
\hline Breathing frequency, breaths/min & $33(31.9-34.3)$ & $33(31.7-34.4)$ \\
\hline $\mathrm{S}_{\mathrm{pO}_{2}}, \%$ & $84.8(83.7-85.6)$ & $85.6(84.4-86.9)$ \\
\hline \multicolumn{3}{|c|}{ Physiology at study entry, $n$, mean $(95 \% \mathrm{CI})$} \\
\hline $\mathrm{F}_{\mathrm{IO}_{2}}$ & $130,0.38(0.36-0.41)$ & $102,0.38(0.35-0.41)$ \\
\hline Breathing frequency, breaths/min & $154,29.9(28.8-31)$ & $119,28.7(27.4-30)$ \\
\hline $\mathrm{S}_{\mathrm{pO}_{2}}, \%$ & $156,91.4(90.4-92.3)$ & $131,91.9(91-92.9)$ \\
\hline Heart rate, beats/min & $158,101(97-104)$ & $131,109(105-112)$ \\
\hline Systolic blood pressure, $\mathrm{mm} \mathrm{Hg}$ & $154,137(132-142)$ & $126,143(137-149)$ \\
\hline Diastolic blood pressure, $\mathrm{mm} \mathrm{Hg}$ & $153,73(70-76)$ & $126,77(74-80)$ \\
\hline Temperature, ${ }^{\circ} \mathrm{C}$ & $116,37.1(36.9-37.3)$ & $98,37.4(37.2-37.7)$ \\
\hline \multicolumn{3}{|c|}{ Physiology at study entry, $n$, median (IQR) } \\
\hline GCS & $112,15(15-15)$ & $94,15(15-15)$ \\
\hline \multicolumn{3}{|l|}{ Initial working diagnosis, $n, \%(95 \% \mathrm{CI})$} \\
\hline COPD & $46,27.9(22-35)$ & $33,23.9(18-32)$ \\
\hline Pneumonia & $34,20.6(15-27)$ & $38,27.5(21-36)$ \\
\hline Heart failure & $26,15.8(11-22)$ & $17,12.3(8-19)$ \\
\hline Mixed & $29,17.6(12-24)$ & $17,12.3(8-19)$ \\
\hline Asthma & $7,4.2(2-9)$ & $13,9.4(6-16)$ \\
\hline Other & $7,4.2(2-9)$ & $5,3.6(1-8)$ \\
\hline Not stated & $16,9.7(6-15)$ & $15,10.9(7-17)$ \\
\hline \multicolumn{3}{|l|}{ Investigations, $n, \%(95 \% \mathrm{CI})$} \\
\hline Arterial blood gas & $74,44.9(37-52)$ & $60,43.5(35-52)$ \\
\hline Venous blood gas & $77,46.7(39-54)$ & $65,47.4(39-55)$ \\
\hline CXR & $165,100(97-100)$ & $137,99.3(96-100)$ \\
\hline CT chest & $1,0.6(0-4)$ & $4,2.9(1-7)$ \\
\hline \multicolumn{3}{|l|}{ Treatments, $n, \%(95 \% \mathrm{CI})$} \\
\hline Antibiotic & $107,64.8(57-72)$ & $81,58.7(50-67)$ \\
\hline Steroid & $43,26.1(20-33)$ & $36,26.1(19-34)$ \\
\hline Salbutamol & $76,46.1(39-54)$ & $58,42(34-50)$ \\
\hline Ipratropium & $47,28.5(22-36)$ & $39,28.3(21-36)$ \\
\hline Furosemide & $30,18.2(13-25)$ & $26,18.8(13-26)$ \\
\hline Intravenous vasodilator & $1,0.6(0-4)$ & $2,1.5(0-5)$ \\
\hline Intravenous vasopressor & $1,0.6(0-4)$ & $1,0.7(0-4)$ \\
\hline Intravenous fluid & $20,12.1(8-18)$ & $15,10.9(7-17)$ \\
\hline \multicolumn{3}{|l|}{ Treatment, mean $(95 \% \mathrm{CI})$} \\
\hline Volume intravenous fluid, $\mathrm{mL}$ & $1,295(1,105-1,484)$ & $1,264(1,040-1,487)$ \\
\hline \multicolumn{3}{|l|}{$\begin{array}{l}\text { HFNC = high-flow nasal cannula } \\
\text { IQR }=\text { interquartile range } \\
\text { GCS = Glasgow coma score } \\
\text { CXR = chest radiograph } \\
\text { CT }=\text { computed tomography }\end{array}$} \\
\hline
\end{tabular}



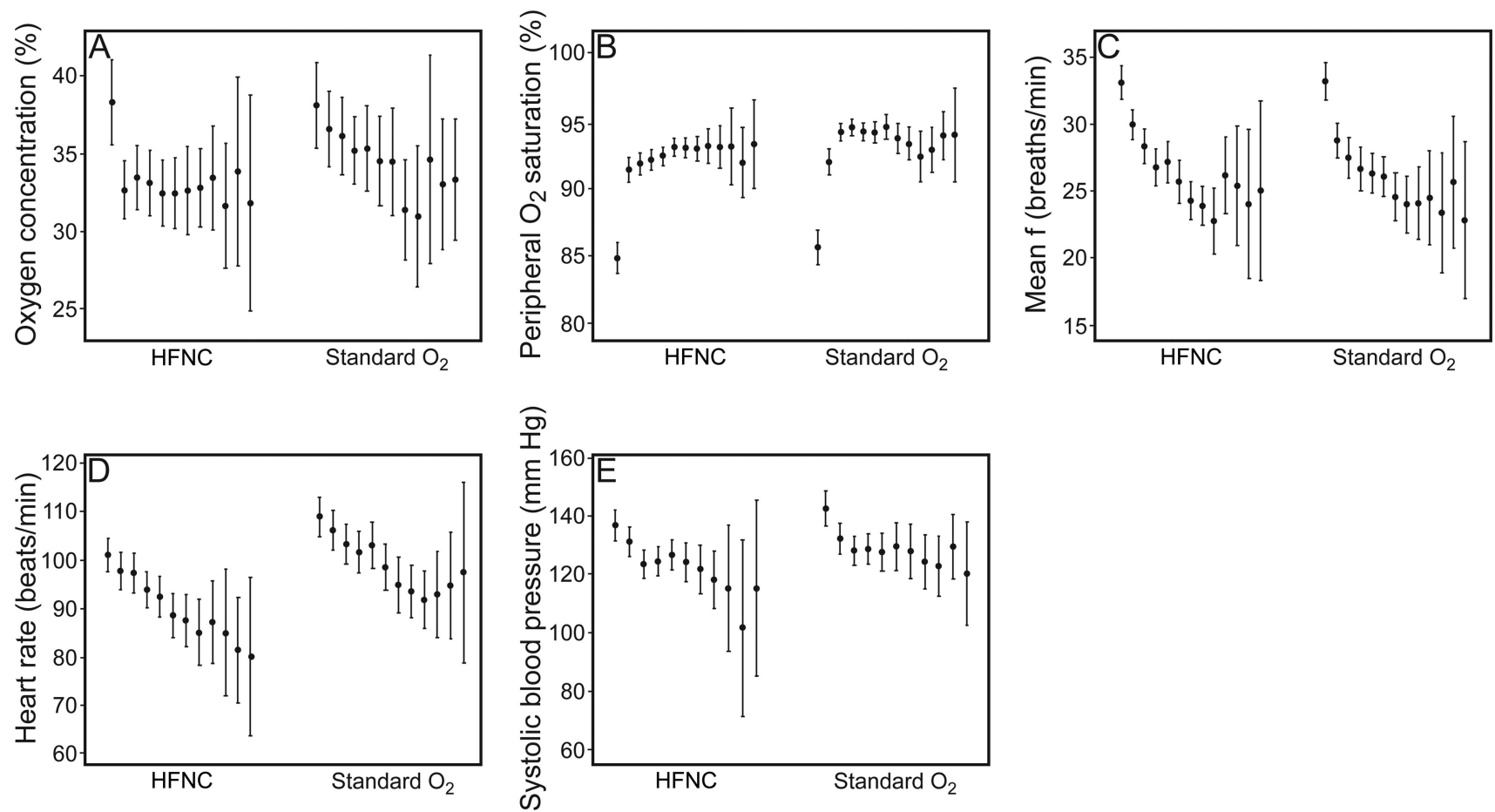

Fig. 2. Physiological variables. For peripheral oxygen saturation (B) and breathing frequency $(C)$, the leftmost data point represents the mean value at presentation either pre-hospital or in the emergency department (these were the physiological inclusion criteria for the study). The next data point is T0, immediately before randomization. Subsequent data points are T1-T11, representing half-hourly intervals of treatment during emergency department stay. For the other variables, the data points are T0-T11. Data are shown as mean (95\% Cl).

$71 / 93,76.3 \%(95 \%$ CI $67-84 \%), P=.044$. There was a difference in the proportion of participants who felt that HFNC was worse than previous oxygen therapy compared with those who received standard $\mathrm{O}_{2}: 17 / 85,20 \%$ (95\% CI $13-30 \%$ ) versus $3 / 57,5.3 \%$ (95\% CI $1-15 \%)$, $P=.01$. Free text comments reflected survey scores, with generally positive comments about both therapies; however, 13 participants felt that HFNC was too hot, compared with only 1 in the standard $\mathrm{O}_{2}$ group (rest of data not shown).

\section{Post Hoc Exploratory Analyses}

Only $13 / 303,4.3 \%$ (95\% CI 2-7\%) participants were admitted to the ICU, and 4, 1.3\% (95\% CI 0-3\%) required endotracheal intubation with no difference between the groups (Table 2). In-hospital mortality was the same 15/156, 9.1\% (95\% CI 6-15\%) in the HFNC group and $11 / 138,8.0 \%$ (95\% CI 4-14\%) in the standard $\mathrm{O}_{2}$ group $(P=.73)$. Fewer participants in the HFNC group required mechanical ventilation either in the emergency department or within $24 \mathrm{~h}$ of leaving the emergency department $9 / 165$, $5.5 \%$ (95\% CI 3-10\%) compared with the standard $\mathrm{O}_{2}$ group, $16 / 138,11.6 \%$ (95\% CI 7-18\%), $P=.05$.

\section{Discussion}

To our knowledge, this is the first randomized controlled study of HFNC in an emergency department. No statistically significant difference in conversion to mechanical ventilation in the emergency department between the groups was demonstrated, and there was also no difference in LOS in the emergency department or the hospital or 90-d mortality. There were few adverse effects, although more participants in the standard $\mathrm{O}_{2}$ group had a clinically important drop in Glasgow coma score than in the HFNC group, which in the 3 cases was due to $\mathrm{CO}_{2}$ retention. This may have been due to the higher $\mathrm{F}_{\mathrm{IO}_{2}}$ and corresponding saturations that were seen in the first few hours of treatment with standard $\mathrm{O}_{2}$. We postulate that this may be due to the ability to titrate $\mathrm{F}_{\mathrm{IO}_{2}}$ more precisely with the HFNC device compared with wall oxygen. However, because few participants suffered this adverse event, it may simply have been a chance occurrence.

The subject experience survey showed that most participants were happy with the oxygen delivery method that they received, although approximately 1 in 12 participants did not tolerate HFNC. One prior case series of 17 participants found that HFNC was well tolerated in the emergency department setting with improved dyspnea scores; however, the study was an uncontrolled before and after 
Table 2. Outcomes

\begin{tabular}{|c|c|c|c|}
\hline Outcome & $\operatorname{HFNC}(n=165)$ & Standard $\mathrm{O}_{2}(n=138)$ & $P$ \\
\hline Conversion to mechanical ventilation in emergency department, $n$, \% (95\% CI) & $6,3.6(1.5-7.9)$ & $10,7.2(3.8-13)$ & .16 \\
\hline 90-d mortality, $n, \%(95 \% \mathrm{CI})$ & $35,21.2(15.6-28.1)$ & $24,17.4(11.9-24.6)$ & .40 \\
\hline Pneumothorax, $n, \%(95 \% \mathrm{CI})$ & $0,0(0-3)$ & $0,0(0-3)$ & \\
\hline Subcutaneous emphysema, $n, \%(95 \% \mathrm{CI})$ & $0,0(0-3)$ & $0,0(0-3)$ & \\
\hline Pressure sore, $n, \%(95 \% \mathrm{CI})$ & $0,0(0-3)$ & $0,0(0-3)$ & \\
\hline Apnea, $n, \%(95 \% \mathrm{CI})$ & $0,0(0-3)$ & $1,0.7(0-4)$ & .45 \\
\hline Fall in GCS $\geq 2$ points, $n, \%(95 \% \mathrm{CI})$ & $1,0.6(0-3.7)$ & $6,4.3(1.8-9.4)$ & .050 \\
\hline Fall in GCS due to $\mathrm{CO}_{2}$ retention,* $n, \%(95 \% \mathrm{CI})$ & $0,0(0-3)$ & $3,2.2(0.4-6)$ & .09 \\
\hline Intubated, $* n, \%(95 \% \mathrm{CI})$ & $1,0.6(0-4)$ & $3,2.2(0.5-6)$ & .33 \\
\hline Admitted to ICU,* $n, \%(95 \% \mathrm{CI})$ & $8,4.8(2.3-9.4)$ & $5,3.6(1.3-8.4)$ & 60 \\
\hline Mechanical ventilation within $24 \mathrm{~h}, * n, \%(95 \% \mathrm{CI})$ & $9,5.5(2.8-10.2)$ & $16,11.6(7.2-18.1)$ & .053 \\
\hline In-hospital mortality, ${ }^{*} n, \%(95 \% \mathrm{CI})$ & $15,9.1(5.5-14.6)$ & $11,8.0(4.4-13.8)$ & .73 \\
\hline Emergency department LOS, median (IQR) h & $4.5(3.6-5.8)$ & $4.9(3.6-5.9)$ & .32 \\
\hline Hospital LOS, median (IQR) d & $5.0(2.8-8.3)$ & $5.6(2.8-9.3)$ & .43 \\
\hline Time to mechanical ventilation in emergency department, ${ }^{*}$ median (IQR) min & $6,139.5(70-214.5)$ & $10,126(19.75-197.75)$ & .43 \\
\hline Time to mechanical ventilation in ward,* median (IQR) $\min$ & $3,1,040(755.5-1,222.5)$ & $6,857(395-1,116)$ & .71 \\
\hline $\begin{array}{l}\text { * Post hoc analyses. } \\
\text { HFNC = high-flow nasal cannula } \\
\text { GCS = Glasgow coma score } \\
\text { LOS = length of stay } \\
\text { IQR = interquartile range } \\
\text { Mechanical ventilation includes noninvasive and invasive ventilation. }\end{array}$ & & & \\
\hline
\end{tabular}

study and was too small to allow firm conclusions about tolerability to be drawn. ${ }^{12}$

Post hoc analysis suggested that there may be a benefit of HFNC beyond the first few hours in the emergency department, with fewer participants requiring subsequent escalation of oxygen therapy on the ward in the first $24 \mathrm{~h}$ of admission. This analysis should be interpreted with caution because it was not preplanned, and the decision to escalate oxygen therapy was an arbitrary one made by the treating ward clinicians.

Two randomized controlled trials of HFNC versus standard $\mathrm{O}_{2}$ in adults have occurred in the ICU setting. In the first of these, there was no difference in oxygenation, ICU, or hospital LOS for 340 post-cardiac surgery subjects. ${ }^{15}$ There was a small difference in $\mathrm{P}_{\mathrm{aCO}_{2}}(1.5 \mathrm{mmHg})$ favoring HFNC. Similar to our study, participants found standard $\mathrm{O}_{2}$ more comfortable than HFNC, although both treatments rated highly on the scale of comfort used. Contrary to our study, $6.5 \%$ of participants in their HFNC group required NIV or invasive positive-pressure ventilation compared with $2.9 \%$ in the standard $\mathrm{O}_{2}$ group. The differences with respect to this outcome observed in both studies may simply be due to chance. However, it is also plausible that differences in the study populations may account for the difference in the direction of effect observed. In the second study, in 310 subjects with hypoxic respiratory failure without hypercarbia (the majority of whom had pneumonia), HFNC was compared with standard $\mathrm{O}_{2}$ and NIV given for 2 days. There was no difference in intubation rates; however, there was a mortality benefit in favor of HFNC over both comparator groups. ${ }^{16}$ This may have been due to factors other than the oxygen delivery method, because more subjects in the standard $\mathrm{O}_{2}$ and NIV groups had refractory shock as the cause of death than HFNC subjects. In this study, HFNC was tolerated better than both comparator oxygen delivery systems, with no subjects reported to be intolerant of either HFNC or NIV therapy, which differs from our study. Because only $10 \%$ of patients with acute respiratory failure were eligible and only $6 \%$ were finally included, the generalizability of this study is limited to a highly select group of patients, which is different from the majority of patients who present to the emergency department in respiratory distress. In contrast, we recruited all subjects regardless of underlying reason for respiratory distress, which we believe is a strength of the current study because it reflects clinical reality in the emergency department. Oxygen therapy is started for patients with acute respiratory distress and hypoxia upon arrival in the emergency department when the underlying diagnosis or the risk of hypercarbia may not be clear.

The most important limitation of our study was the failure to achieve the initially estimated sample size, which was due to more subjects being excluded from selection and fewer subjects requiring NIV than we had anticipated. This is especially relevant because 27 patients were excluded because the treating clinician placed them on NIV immediately upon arrival without considering them for the study, meaning that some severely hypoxic patients were excluded from the study because clinicians were not comfortable with delaying NIV even for $30 \mathrm{~min}$ to deliver the 
Table 3. Respiratory Physiology During First $3 \mathrm{~h}$ of Treatment

\begin{tabular}{|c|c|c|c|c|}
\hline Variable & $\operatorname{HFNC}(n=165)$ & Standard $\mathrm{O}_{2}(n=138)$ & Difference, Mean (95\% CI) & $P$ \\
\hline \multicolumn{5}{|l|}{ Inspired $\mathrm{O}_{2}, n$, mean $\%$} \\
\hline T0 & $130,38.4$ & $102,38.2$ & $0.2(-3.7$ to 4.1$)$ & .92 \\
\hline $\mathrm{T} 1$ & $151,32.7$ & $115,36.6$ & $-3.9(-6.9$ to -0.9$)$ & .01 \\
\hline $\mathrm{T} 2$ & $143,33.5$ & $107,36.2$ & $-2.7(-5.8$ to 0.5$)$ & .10 \\
\hline $\mathrm{T} 3$ & $129,33.2$ & $97,35.3$ & $-2.1(-5.1$ to 1$)$ & .18 \\
\hline $\mathrm{T} 4$ & $110,32.5$ & $83,35.4$ & $-2.9(-6.3$ to 0.5$)$ & .10 \\
\hline T5 & $91,32.5$ & $68,34.6$ & $-2.1(-5.7$ to 1.6$)$ & .26 \\
\hline T6 & $67,32.7$ & $44,34.5$ & $-1.8(-6.3$ to 2.6$)$ & .41 \\
\hline \multicolumn{5}{|l|}{$\mathrm{S}_{\mathrm{pO}_{2}}, n$, mean $\%$} \\
\hline T0 & $156,91.4$ & $131,91.9$ & $-0.5(-1.9$ to 0.73$)$ & .39 \\
\hline $\mathrm{T} 1$ & $145,91.8$ & $109,94.1$ & $-2.3(-3.4$ to -1.3$)$ & $<.01$ \\
\hline $\mathrm{T} 2$ & $130,92.1$ & $96,94.5$ & $-2.4(-3.4$ to -1.4$)$ & $<.01$ \\
\hline $\mathrm{T} 3$ & $126,92.3$ & $88,94.2$ & $-1.9(-2.8$ to -0.9$)$ & $<.01$ \\
\hline $\mathrm{T} 4$ & $108,93.0$ & $82,94.1$ & $-1.1(-2.1$ to -0.7$)$ & .04 \\
\hline T5 & $95,93.0$ & $63,94.5$ & $-1.5(-2.7$ to -0.4$)$ & .01 \\
\hline T6 & $64,92.9$ & $45,93.7$ & $-0.8(-2.1$ to 0.6$)$ & .29 \\
\hline \multicolumn{5}{|c|}{ Breathing frequency, $n$, mean breaths/min } \\
\hline T0 & $154,29.9$ & $119,28.7$ & $1.2(-0.5$ to 2.9$)$ & .16 \\
\hline $\mathrm{T} 1$ & $125,28.3$ & $104,27.4$ & $0.9(-1.1$ to 2.8$)$ & .39 \\
\hline $\mathrm{T} 2$ & $115,26.7$ & $85,26.6$ & 0.1 ( -2 to 2.2$)$ & .92 \\
\hline $\mathrm{T} 3$ & $109,27.1$ & $80,26.3$ & $0.8(-1.3$ to 1.1$)$ & .44 \\
\hline $\mathrm{T} 4$ & $91,25.7$ & 73,26 & $-0.3(-2.6$ to 1.1$)$ & .74 \\
\hline T5 & $81,24.3$ & $57,24.5$ & $-0.2(-2.5$ to 1.1$)$ & .81 \\
\hline T6 & $58,23.9$ & 41,24 & $-0.1(-2.5$ to 1.2$)$ & .93 \\
\hline
\end{tabular}

HFNC $=$ high-flow nasal cannula

$\mathrm{T}=$ half-hourly time interval from study entry: $\mathrm{T} 0$ is immediately prior to study treatment, and $\mathrm{T} 1$ is the first half hour after study treatment started.

Table 4. Subject Experience Survey Results

\begin{tabular}{|c|c|c|c|}
\hline Survey Question & $\operatorname{HFNC}(n=94)^{*}$ & Standard $\mathrm{O}_{2}(n=64)$ & $P$ \\
\hline Felt comfortable & $69 / 94,74.2(64-81)$ & $55 / 64,85.9(75-93)$ & .08 \\
\hline Breathing not improved & 19/93, $20.4(13-30)$ & $18 / 63,28.6 \%(19-41)$ & .24 \\
\hline Dry nose or mouth & 28/94, $29.8(21-40)$ & $29 / 64,45.3(34-57)$ & .046 \\
\hline Breathing easier & 76/93, $81.7(73-88)$ & $46 / 64,71.9(60-81)$ & .15 \\
\hline I would be happy to have it again & $71 / 93,76.3(67-84)$ & 57/64, $89.1(79-95)$ & .044 \\
\hline It was worse than what I've had before $(n=142) \dagger$ & $17 / 85,20.0(13-30)$ & $3 / 57,5.3(1-15)$ & .01 \\
\hline \multicolumn{4}{|c|}{$\begin{array}{l}\text { Values are shown as } n \text { valid (not all participants answered all questions) } / n, \%(95 \% \mathrm{CI}) \text {. See the appendix for survey questions that were analyzed as dichotomous data: } 5 \text {-point Likert scale. The best } \\
2 / \text { ther } 3 \text { or worst } 2 / \text { other } 3 \text { categories were collapsed for positive and negative questions, respectively. } \\
* \text { Not all participants answered all questions. } \\
\dagger \text { Eight participants in the humidified high-flow nasal oxygen group and } 7 \text { in the standard delivery oxygen group had not had previous oxygen therapy; the maximum denominators for this outcome } \\
\text { are } 86 \text { and } 57 \text {, respectively. } \\
\text { HFNC = high-flow nasal cannula }\end{array}$} \\
\hline
\end{tabular}

study interventions. Therefore, it is possible that the included study participants were not as severely unwell as the pilot study population. Compounding this, only 1 in 20 of the trial participants was escalated to NIV when stricter parameters for the use of NIV were applied during the study, compared with 1 in 4 trial-eligible patients in the pre-study period when NIV use was solely at the clinician's discretion. These 2 factors biased against finding a difference between the study interventions, which means that our sample size calculation was inaccurate to the point that the current study should be regarded as a pilot to inform future research into the use of HFNC in the emergency department. We performed a post hoc sample size calculation and found that a study would need approximately 900 subjects to have sufficient power to detect the difference that we observed in the primary outcome. At our recruitment rate, this meant that we would have needed to run the study for $4.5 \mathrm{y}$ to achieve this sample size, 
which was not feasible at our center with the funding and resources available. Because the study was not blinded, clinicians may have altered their treatment decisions based on which intervention the participant was receiving; however, we do not think that this was the case, because other treatments received were similar between the groups.

Not all participants had observations recorded at every half-hourly time point, which was not possible due to our reliance on clinical staff to record these as part of routine care. As subjects improved, the time interval between recorded observations increased. This limits the strength of our conclusions relating to differences in respiratory physiology observed, although the biggest difference occurred in the first $2 \mathrm{~h}$, when most participants had observations done. A further limitation relates to the small number of participants who were intubated or went to the ICU, despite this being a very unwell cohort of subjects, with baseline severity of hypoxia and breathing frequencies similar to the most recent ICU study. ${ }^{16}$ This means that the results we observed may not be generalizable to settings where invasive positive-pressure ventilation and ICU admission are offered to a wider range of patients, with a bias against showing a difference between the interventions for these outcomes in our study. In a large case series of pediatric emergency department subjects who needed subsequent ICU care, introduction of HFNC in the emergency department was associated with fewer intubations in the emergency department, although there was no control group in this study, so this may have been due to other factors. ${ }^{17}$

\section{Conclusions}

HFNC was not shown to reduce the need for NIV or invasive positive-pressure ventilation in the emergency department for subjects with acute respiratory distress compared with standard $\mathrm{O}_{2}$, which may be due to the study being underpowered to detect the observed small absolute difference. However, HFNC may reduce the need for escalation of oxygen therapy within the first $24 \mathrm{~h}$ of admission. There were no clinically important adverse events associated with HFNC use; however, 1 in 12 subjects was intolerant of HFNC therapy.

\section{ACKNOWLEDGMENTS}

We thank the nurses and doctors in the Auckland City Hospital Adult Emergency Department, without whom the study would not have been possible; the late Trish O'Malley for data entry; and Dinesh Kumar for database design. Fisher and Paykel Healthcare provided equipment for the study, specifically the humidifiers and consumables (tubing and nasal interface) required to deliver humidified high-flow oxygen.

\section{REFERENCES}

1. Mayfield S, Jauncey-Cooke J, Hough JL, Schibler A, Gibbons K, Bogossian F. High-flow nasal cannula therapy for respiratory support in children. Cochrane Database Syst Rev 2014;(3):CD011010.

2. Dysart K, Miller TL, Wolfson MR, Shaffer TH. Research in high flow therapy: mechanisms of action. Respir Med 2009;103(10):14001405.

3. Waugh JB, Granger WM. An evaluation of 2 new devices for nasal high-flow gas therapy. Respir Care 2004;49(8):902-906.

4. Armfield M, West G. Use of Vapotherm for respiratory support with neonates. Paediatr Nurs 2009;21(1):27-30.

5. Foster K, Hough J, Pham T, Schibler A. High flow nasal prong oxygen (HFNP) reduces the need for mechanical ventilation in bronchiolitic infants. The Asia Pacific Critical Care 2008 Congress. Aust Crit Care 2009;22(1):46-47.

6. Saslow JG, Aghai ZH, Nakhla TA, Hart JJ, Lawrysh R, Stahl GE, Pyon KH. Work of breathing using high-flow nasal cannula in preterm infants. J Perinatol 2006;26(8):476-480.

7. Campbell DM, Shah PS, Shah V, Kelly EN. Nasal continuous positive airway pressure from high flow cannula versus infant flow for preterm infants. J Perinatol 2006;26(9):546-549.

8. Kubicka ZJ, Limauro J, Darnall RA. Heated, humidified high-flow nasal cannula therapy: yet another way to deliver continuous positive airway pressure? Pediatrics 2008;121(1):82-88.

9. Wilkinson D, Andersen C, O’Donnell CP, De Paoli AG. High flow nasal cannula for respiratory support in preterm infants. Cochrane Database Syst Rev. 2011;(5):CD006405.

10. Beggs S, Wong ZH, Kaul S, Ogden KJ, Walters JAE. High-flow nasal cannula therapy for infants with bronchiolitis. Cochrane Database Syst Rev 2014;(1):CD009609.

11. Lee JH, Rehder KJ, Williford L, Cheifetz IM, Turner DA. Use of high flow nasal cannula in critically ill infants, children, and adults: a critical review of the literature. Intensive Care Med 2013;39(2):247-257.

12. Lenglet H, Sztrymf B, Leroy C, Brun P, Dreyfuss D, Ricard JD. Humidified high flow nasal oxygen during respiratory failure in the emergency department: feasibility and efficacy. Respir Care 2012; 57(11):1873-1878

13. Wagstaff TA, Soni N. Performance of six types of oxygen delivery devices at varying respiratory rates. Anaesthesia 2007;62(5):492-503.

14. British Thoracic Society Standards of Care Committee. Non-invasive ventilation in acute respiratory failure. Thorax 2002;57(3):192-211.

15. Parke R, McGuinness S, Dixon R, Jull A. Open-label, phase II study of routine high-flow nasal oxygen therapy in cardiac surgical patients. Br J Anaesth 2013;111(6):925-931.

16. Frat JP, Thille AW, Mercat A, Girault C, Ragot S, Perbet S, et al. High-flow oxygen through nasal cannula in acute hypoxemic respiratory failure. N Engl J Med 2015;372(23):2185-2196.

17. Wing R, James C, Maranda LS, Armsby CC. Use of high-flow nasal cannula support in the emergency department reduces the need for intubation in pediatric acute respiratory insufficiency. Pediatr Emerg Care 2012;28(11):1117-1123.

This article is approved for Continuing Respiratory Care Education credit. For information and to obtain your CRCE

(free to AARC members) visit

www.rcjournal.com

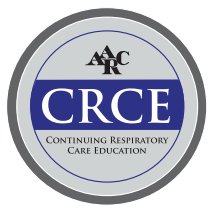

